\title{
Study on Curriculum Internationalization of the Undergraduates of Agricultural Colleges Based on Bilingual Teaching in China
}

\author{
Wu shihong ${ }^{1}$,Ji Jianwei,Cao Yingli,Zhang Zhixia,Huang Rui,Yang Ping,Wang Jue \\ College of Information and Electrical Engineering, Shenyang Agricultural University \\ Shenyang, China \\ ${ }^{1}$ Shihong.1@163.com
}

\begin{abstract}
The internationalization of higher agricultural education was promoted by economic globalization in China, especially, the internationalization of undergraduate courses as a key component of it has also developed rapidly, but not perfect. The necessities were expounded and the current main problem in the internationalization of undergraduate course was analyzed. At the same time, combined with the teaching practice of the bilingual teaching, how to choose the curriculum contents and teaching materials of the internationalization of general education with the characteristics of the internationalization and how to set up diversified foreign language courses and promote the bilingual teaching actively, etc. were discussed in this paper. and in view of the problem of the internationalization of university undergraduate course in China, the feasible strategies were put forward, which establish the standardized management mode for curriculum internationalization, use modern teaching carrier to implement curriculum internationalization, promote the teaching ability of internationalization courses of faculties and constantly raise the level of curriculum internationalization of higher agricultural colleges.
\end{abstract}

Keywords-curriculum internationalization of undergraduate; Higher agricultural colleges; Bilingual teaching

\section{INTRODUCTION}

Internationalized talents refer to those who have the knowledge and ability in both at home and abroad affairs under the broad international vision, and have the ability to interpret other cultures in the language. If a nation wants to be in a competitive advantage in the world, there must be good international talents with global consciousness in this nation. In China, international awareness and action has not been enhanced to a satisfactory degree in terms of talent training, In the aspect of teaching, one of the major performance is that the form, content of courses and teaching methods are not high in the internationalization degree .With the development of China's economy, politics, culture, the task of cultivating international talents is becoming more and more heavy, in which the requirement of our university undergraduate courses must be urgent reformed .One of the main points of the reform is to reform the course contents, form, teaching methods and so on to promote the comprehensive reform of

2014education teaching reform project of undergraduate course of common colleges and universities in liaoning province(UPRP20140488). internationalizations and improve the level of internationalization.

Curriculum is the core of education content, to realize internationalization of higher education, the internationalization of curriculum is one of the important means, without the internationalization course, modernization of university will lose its most essential features. So it is the requirement of the modernization of the university to study the internationalization of undergraduate curriculum in China.

Curriculum system is reasonable or not, which will be directly related to the quality of fostering talents, and embodies the talent training mode and teaching characteristics of university. To cultivate international talents in China, the course content will be updated along with the change of the information society, the course system must make corresponding adjustment and innovation, curriculum internationalization is one of the important measures. University as "the cradle of training and bring up high quality talents", should have the courage to face all the challenges brought by the internationalization of higher education ${ }^{[1]}$, and study and solve the new problems of higher education seriously, try to take and introduce foreign advanced training mode, teaching contents and teaching methods. Because the course is a major means of producing the international talents, to cultivate highly qualified international talents, a variety of international courses are needed. The main way is to absorb foreign advanced curriculum structure and fuse local features, through curriculum system innovation, the cultivation of international talents will be achieved.

\section{PROBLEMS OF THE INTERNATIONALIZATION OF UNDERGRADUATE CURRICULUM IN CHINA}

\section{A. Incomplete foreign language curriculum and low teaching level of listening and speaking}

Higher education in many non-native English countries is also very developed .To further understand the concept of higher education in these countries and the current situation of the courses, you must master their languages, which is not concerned during the development and construction of the course of foreign language in China. Almost all of the universities teach English for all students of English as a 
compulsory course, other language curriculum is very limited, or just as an elective course and attention is not enough. There currently are problems of time consuming more and low efficiency in foreign language teaching in China. Although many college students have been studying a foreign language for 8 or 12 years, but could not reach the requirements of skilled reading original books, it is difficult to communicate directly with foreigners, which shows that level of foreign language teaching can't meet the international demand, can't meet the requirement of the development of the international community.

\section{B. Insufficient teachers with international teaching ability}

Currently, when undergraduate courses are internationalized in China, it is hard to hire teachers with the internationalization of the teaching experience and ability, and be able to put them into the teaching .In order to build our university undergraduate courses of internationalization, the internationalization construction of teachers must be put more attention meanwhile to raise the internationalization course teaching ability. Many universities in our country attaché great importance to the international experience of teachers in recent years, a large number of teachers are sent abroad to study or to international academic exchanges, which ,to some extent, is conducive to the construction of internationalization of teachers .However, due to some factors, many university teachers less chance to go abroad to "recharge". The rapid expansion of scale of domestic university leads to serious shortage of teachers, student-faculty ratios were as high as 40:1 in some universities, so in order to make up for shortage, many universities are forced to reduce the recruitment conditions, even with the phenomenon of corruption. Such teachers are hard to adapt to the requirement of internationalization. Because of reasons of China's policy and funding, limited number of foreign teachers, it is difficult to fully meet the needs of the internationalization of university undergraduate courses. At the same time, most of the employed foreign teachers are all foreign language teachers, only a small part of them engage in the work of the professional course teaching.

\section{The set of general education courses can not meet the international demand}

General education courses try to let students in the undergraduate education obtain rich and broad knowledge, make students understand there are different research methods and research ideas in the different academic fields and make college students with different personality and ability to master methods and broad horizons needed in the process of learning and development .University general education courses undertake the task to cultivate students most of internationalized vision, general education curriculum content is an important part of the course of internationalization, is also the important trend of the curriculum internationalization .At present, internationalization course in the university undergraduate courses is given priority to with professional class and make a professional course for another professional general education courses .In this way, not only cannot obtain abundant curriculum resources, but also difficult to improve the students' overall quality, and the internationalization of the curriculum will not be realized .
International talents are demanded to have rich interdisciplinary knowledge, but in the absence of relevant professional basis, students choose to study other professional courses can't reach the purpose of the study interdisciplinary knowledge. At present, the college general education subjects embody less frontier dynamic and introduction of new subjects. The general education curriculum reflecting the interdisciplinary and comprehensive development of is woefully inadequate. This situation is fail to conducive to the construction of a reasonable knowledge structure of students and the improvement of comprehensive quality and innovation ability, and can't meet requirements of curriculum internationalization.

\section{MEASURES OF PROMOTING INTERNATIONALIZATION OF UNDERGRADUATE CURRICULUM IN CHINA}

\section{A. An overview of the connotation of international talents training target}

The main purpose of the course of internationalization is to cultivate international talents with international vision and can participate in international competition. Therefore, in order to cultivate internationalized talents, first of all, there must be internationalized talents training target. It can provide guidance and direction for cultivating international talents. Since the $1990 \mathrm{~s}$, many countries in the world have been making targets of the cultivation of international talents. Through the curriculum internationalization of higher education, the talent training goal of improving students "global consciousness" and "international concept" can be achieved. ${ }^{[2]}$

\section{B. Setting curriculum under the guidance of international idea and theory}

University curriculum internationalization is not only a communication of course resources and sharing of information communication, but also a concept of running a school. At present, universities in China want to overcome traditional conservative ideas and narrow concepts of local, expand horizons, to realize the importance and necessity of internationalization thought and theory to establish the thinking line of development of university undergraduate course internationalization in China and transform the internationalization into school ethos. Try to create conditions to improve the international level of courses, with which to improve the quality and level of higher education.

\section{Establishing a standardized management style for curriculum internalization}

The course of internationalization of the United States is the reflection of its global development strategy in the higher education, which relates to normative management mode of the department in charge of education, the form of regulations and policies of institutionalization. With the support of relevant laws, the United States governments invest more in higher education, many universities set up scholarship program to attract international students from all over the world to improve the effect on the implementation of curriculum internationalization. By contrast, "the concept of curriculum internationalization" hasn't explicitly appeared in the text of 
some policy in China, which is against the development of university curriculum internationalization. Therefore, the relevant government departments should increase investment in education in China, and promulgate special policy documents for the internationalization of curriculum establish the corresponding management way, strengthen the institutionalization of management to improve the level of the internationalization of university undergraduate course in China.

The competent departments of education in China also provide specialized financial support for the implementation of internalization of undergraduate course .The main body of financial support includes government, social organizations, individuals, legal persons and institutions of higher learning itself, etc. In the process of implementation of curriculum internationalization in China, it is necessary to fully arouse the enthusiasm of the investment subject, reasonable financing and capital allocation, realize the virtuous circle and improve the level of internationalization of undergraduate course in China effectively.

\section{Establishing a standardized management style for curriculum internalization}

The main purpose of internationalization of curriculum is to cultivate students' ability to survive in the international and multicultural environment, namely a course designed for students at home and abroad. It should have the characteristics of the internationalization on the choice of course content and teaching material. The internationalization of general education courses plays an important role in improving the quality of students, enhancing students' international awareness and cross-cultural ability. Therefore, the internationalization of general education curriculum content with the characteristics of internalization should be chosen on the basis of universality of knowledge according to their own development goals. In order to make the general education curriculum to achieve the requirement of the internationalization, the special international general education courses should be set up in university undergraduate course in China, so that the students ,through general education, fully understand the relationship between countries, as well as the universality of problems such as racial discrimination and poverty. Some content of the internationalization should be added in the existed general education courses and absorb the similar foreign materials on the general curriculum content, the content closely on the latest developments of general education courses in the world.

Choosing materials of internationalization characteristics is also the basis for the implementation of university undergraduate course of internationalization in China. Therefore, internationalization of university undergraduate course in China should introduce the foreign original teaching materials and provide more direct international approach to learning. ${ }^{[3]}$ In order to develop a road with characteristic of our national curriculum internationalization, teachers in conditional universities can strengthen cooperation with foreign press to adapte some original edition textbooks, independent writing or working with foreign professional teachers to write the internationalization teaching materials in accordance with of curriculum system in China.

\section{E. Setting up diversified foreign language courses and promoting actively the bilingual teaching}

In the process of curriculum internationalization, colleges and universities should actively communicate with foreign universities equally; you need a variety of language as a communication tool. Although English as an international common language plays an important role in the course of internationalization, if you only get English, then it is at the risk of bias, and a full range of international communication of the true sense can't be realized. So setting of the curriculum should not only confine to the English, and should open a variety of languages. ${ }^{[4]} \mathrm{We}$ encourage students to improve their English, students can master another language.

In the course of internationalization, bilingual teaching is an important way of teaching, which is the important way to cultivate high quality talents with international vision and the international competitiveness. Bilingual teaching is beneficial to improving the level of university curriculum internationalization, however, how to actively promote, different universities should choose according to their own different operating conditions. For those colleges with relatively weak base of teachers and students should take more effective measures create favorable conditions and choose standard breakthrough for the experiment of bilingual teaching.

Bilingual teaching is a teaching with a high implementation cost .On course selection, we need to learn a foreign high-tech fields, need a comparative study, with comparable discipline field both at home and abroad, and make a active propaganda of culture in China. ${ }^{[5]}$ In terms of the teaching mode, we should seek suitable for different types and levels of students of hierarchical teaching model. According to students' actual language level and professional level, they are arranged into different bilingual classes according to their aptitude.

\section{F. Using the modern teaching carrier to conduct the internationalization of curriculum teachin $g$}

The use of modern teaching carrier is an important approach to the implementation of curriculum internationalization. Carrier includes multimedia classroom, modern science and modern teaching experimental center and multi-functional language LABS and a relatively perfect and advanced teaching service system should be established for it. Modern teaching carrier can comprehensively improve the teachers' teaching environment, teachers adopt the form of multimedia teaching integrated application of words, pictures, video and other data, more intuitive, image to present thinking to students. At the same time, using the Internet to realize resources sharing and in line with international standards, and to realize the communication between teachers, students and society. Modern science experiment center can make students master relevant disciplines of the latest international research results and research dynamic, multi-function voice laboratory can make students' foreign language level are improved effectively. Therefore, when university undergraduate courses are internationalized in China, modern teaching carrier should be used, so that the students' thinking space can be expanded, the way of thinking can be changed, the purpose to broaden the students' international vision can be achieved, which is beneficial to the development of the international talents. 


\section{G. Promoting teacher's abilities of internationalization course teaching}

Teachers with international knowledge and experience are the nucleus force to promote the directional development of university courses internationalization. Teachers have very limited knowledge, only by constantly learn from each other and communication can achieve the goal of mutual promotion and common improvement .At present, the structure of university teachers in China is lack of sufficient teachers with international teaching ability .In order to make our country with international teaching ability, universities can mobilize all aspects of the strength, select the excellent teachers to go abroad for further study so as to cultivate a batch of teachers who can use a foreign language perfectly, use advanced foreign teaching method to teach professional knowledge, grasp the latest research results fully . Introducing foreign intelligence is one way to improve university academic reputation and level, promote the development of university curriculum oriented to internationalization. ${ }^{[6]}$ In order to make our country university teachers have internationalized teaching ability, the measure of introduction of foreign teachers can be taken. The advantage and role of foreign teachers in language teaching can't be taken the place by local teachers, especially in the weak link of writing and listening, to hire foreign teachers to teach ,which reinforce and improve students' foreign language ability clearly. Students can not only learn professional knowledge of the latest dynamic, but also utilize the bilingual writing academic papers and participate in international academic exchanges. Increasing the number of foreign teachers, on the one hand, the internationalization of our country's university teachers teaching can be improved; on the other hand college education ideas, curriculum and teaching contents also develop in the internationalization direction.

\section{H. Using the limited funds to improve the level of curriculum internationalization}

Internationalization of undergraduate courses only under the related policy background support combined with corresponding funding to be able to develop smoothly and effectively. Under the condition of current education investment shortage in China, university curriculum internationalization wants to develop healthily; the level of internationalization of curriculum should be enhanced effectively under the condition of limited funds.

Limited by human resources and material resources, China education of university undergraduate course cannot be achieved all the internationalization course domain, only be within the permitted scope of investment, focus on key construction of various the advantages of university undergraduate disciplines and professional courses to form the local advantage. According to its local advantages, investment areas are expanded, which will achieve more curriculum internationalization of disciplines step by step. ${ }^{[7]}$

The development of information and network breaks the limitation of time of information acquisition and region.. People can know world affairs without leaving home. Universities can share worldwide database, outstanding research results and teachers resources .These changes provide basic conditions for the implementation of the course of internationalization. Therefore, universities should use modern network technology, and use the limited funds to set up the network courses, focus on the foreign advanced internationalization course, master the advanced cultural knowledge. The cultivated students' ability satisfies the standard of international talents. So the level of undergraduate course of internationalization is improved in China.

\section{CONCLUSION}

Curriculum internationalization of university undergraduate courses is the choice to cultivate international talents, the requirement of the modernization of the university and important measures of the university curriculum system innovation in China. Curriculum reform should be carried out in the view of globalization of higher education change, which can promote the internationalization of university undergraduate course effectively in China. In order to meet the needs of the development of the internationalization of higher education, the modern consciousness which is in accordance with international law of development should be established. Some problems mentioned above are overcome constantly and curriculum internationalization is standardized in the form of policies and regulations; using the thinking of the internationalization development to set up curriculum system; through a variety of ways to implement curriculum internationalization; International communication of students and teachers is paid more attention. Applying modern communication technology and developing Moocs, the level of internationalization of agricultural university undergraduate course must be improved in China.

\section{ACKNOWLEDGMENT}

The author would like to thank 2014education teaching reform project of undergraduate course of common colleges and universities in liaoning province (UPRP20140488) for the support of the study.

\section{REFERENCES}

[1] ZHeng Xing, Wang Kun-chen. Quality guarantee system and core mechanism of British higher education system: Also on its enlightenment to quality a ssessment of Chinese higher education. [J] Hunan Agricultural University (Social Sciences) Vol . 14 No. 4: 9296.

[2] Zhang $\mathrm{Xu}, \mathrm{Zhu}$ Liying.The connotation,standard and implementation countermeasures of the internationalization of higher education [J]. Science wenhui, 2007, (02 x) : 1-2.

[3] Introducing foreign intelligence work branch of China's higher education institute, university of internationalization: theory and practice [M]. Beijing: Peking University press, 2007:117.

[4] Xi Youmin,Guo Ju-e,Li Huai-zu. Study on development Features and strategy Chinese university internationalization [M]. Beijing: China renmin university press, 2010:260.

[5] Wu Ping, Wang Shugen .The present situation of the bilingual teaching of research and practical exploration [M]. Beijing: higher education press, 2010:68.

[6] Chen Hao.Discuss of our country's higher education internationalization strategy selection in the new period [J]. Higher Agricultural Education ,2008202,02:14217.

[7] Gao Yurong.Consideration of internationalization of curriculum in colleges and universities [J]. Education Exploration.2010(11): 37-38. 